\title{
A QUESTÃO DO HUMANO E O ANIMAL RATIONALE
}

Pergentino S. Pivatto*

SÍNTESE - A especificação de lógico e político no animal rationale serviu historicamente como determinativo da dimensão humana, e o humano resumiu-se no desenvolvimento destas faculdades. Esta interpretação é contestada no século XX por Scheler, Arendt e Levinas, entre outros, que repõem a questão da relação entre ser, natureza e humano. A problematização ontológico-naturalista leva a repensar a crença naturalista sobre a qual repousa o pensamento antropológico ocidental e desafia a ressignificar o humano a partir de novas compreensões, sobretudo a partir da alteridade.

PALAVRAS-CHAVE - Animal rationale. Sentido do humano. Alteridade.
ABSTRACT - The specificity of the logical and the political in the animal rationale has historically served to determine its human dimension, as the human comes down to the development of these faculties. Such an interpretation has been questioned in the $20^{\text {th }}$ century by Scheler, Arendt and Levinas, among others, who recast the question of the relation between being, nature and the human. The ontological-naturalist problematization leads us to rethink the naturalist belief on which lies Western anthropological thought, as it defies the signification of the human anew from the standpoint of new understandings, especially from alterity's viewpoint. KEY WORDS - Animal rationale. Sense of human. Alterity.

\section{Introdução}

Após os anti-humanismos, a morte do homem e o pós-humanismo, o que ainda se pode esperar de humano do animal racional?

Subsistem, contudo, as Tradições e os testemunhos de humanidade que, embora raros, iluminam a trajetória dramática da espécie dita humana. O que se chama de realidade histórica e cultural não é tecida de testemunhos, de símbolos e de memória?

Talvez convenha retornar ao velho Heráclito, fragmento 93, no qual está escrito: "O mestre cujo oráculo está em Delfos não o anuncia nem o esconde: ele significa". Significar não é fazer sinal, indicar que é possível abrir pistas e, talvez, ressignificar? Aquele ser que apressadamente chamamos de humano não permanece sempre um enigma? Algo de indecifrável, quiçá incompreensível ou, melhor, inesgotável parece constitutivo deste ser. Entre o tudo e o nada, assim ele parece encontrar-se atualmente ao olhar interrogador.

\footnotetext{
* PUCRS, Porto Alegre.
}

\begin{tabular}{|l|l|l|l|l|l|}
\hline VERITAS & Porto Alegre & v. 51 & n. 2 & Junho 2006 & p. 117-127 \\
\hline
\end{tabular}


Por um lado, ineliminável finitude; por outro, ineliminável infinitude para a qual esboça tateante abertura. Finitude inscrita na corporeidade e sua historicidade; infinitude aberta na interioridade como pergunta insilenciável e desejo incompletável, manifestando uma subjetividade dilacerada. O desdobramento da pergunta insilente fica condicionado ao horizonte da exterioridade cósmica infiniforme que provoca e se retrai, se expõe e ameaça; mas a pergunta sobrevoa abismos e subsiste enigmática em sistemas redondos.

Na exterioridade infiniforme, à primeira vista nada se diferencia, tudo é ser, totalidade sem alteridade que aparece como ameaça, cada vez de forma nova e diferente, surpresa que vai exigir do homem exposição, afrontamento, e lenta descoberta como aprendizagem do mundo e de si, domesticação e condicionamento interacionados. Nesta dura aprendizagem, o homem faz experiência de si como arrancando-se da totalidade informe, tecendo a si mesmo e erguendo-se por sobre seus pés, descobrindo a possibilidade de relações diversas com a exterioridade, inclusive a do domínio do real e até de si mesmo. Como uma sombra que acompanha tateamentos, frustrações e sucessos, e marca inexoravelmente a própria historicidade, o fenômeno da vida que se esvai de si e não retorna para si, da luz que se apaga e do respiro que cessa, começa a significar, rompendo a trama da totalidade múltipla e informe que tudo nivela em nascimento e morte. A pergunta insilente desdobra-se em possibilidade de busca de sentido para além do jogo cósmico da multiplicidade natural que o ser manifesta e dos determinismos que regulam a auto-organização da vida. À pergunta que irrompe, quem responderá? o que responder? como significar?

Historicamente, a especificação de racional e político serviu como qualificativo do humano no animal rationale. A partir daí, sempre se justificou que entre razão e natureza não poderia haver oposição, nem entre ética, ao dizer respeito ao político, e natureza, estabelecendo-se a crença de uma integração evolutiva entre vida natural com seus dinamismos, racionalidade, ética e humanidade. A racionalidade e a ética fluem da natureza e no estágio do animal rationale crê-se que especificam a qualidade e o grau deste como humano.

Na multiplicidade e variedade de afrontamentos e relações com a exterioridade, como decifrar e classificar a diferença entre relações cósmicas, relações orgânicas, relações naturais, animais e humanas? À primeira vista, na diferenciação das relações entre determinísticas e significativas e na busca da tipicidade específica parece consistir o humano no homem.

\section{Ponto de partida}

1. Na história do pensamento antropológico, o conhecimento voltado ao homem e sobre ele começa, após os pré-socráticos, com o redirecionamento do olhar do homem sobre si mesmo, deixando de considerar-se a partir da contemplação do cosmos no qual se vê inserido e no qual pretende espelhar-se. "Conhece-te a ti mesmo" é a inscrição que encontram os visitantes de Delfos ao passarem pelo seu pórtico. Em vez de consultar horóscopos ou escutar prenúncios de pitonisas gregas e arúspices romanos, aconselha-se a descoberta do mundo da interioridade, o mergulho no abismo que cada um traz inexplorado em si mesmo. 
2. A classificação ôntica realizada por Aristóteles, subdividindo os seres em minerais, vegetais e animais, reserva para o ser humano algo específico que o distingue dos animais por se relevar racional e político que fica celebrizada na expressão animal rationale. A classificação por diferença específica é contestada por biologistas nos dias atuais, que nela não vêem variação a não ser quantitativa. Além disso, é mister que a definição de homem não seja demasiado simples na sua aplicação. Significa dizer que a classificação parece não ser adequada para o reconhecimento de alguém como humano, mesmo trazendo os caracteres naturais descritos por Aristóteles. O homem, portanto, do ponto de vista de cientistas e humanistas, precisa merecer o título de homem no sentido humano, isto é, precisa passar de homem a humano. Significa dizer que não basta estar ornado de tais e tais características genéticas naturais, como razão, organização, vontade, comunicação, para ser reconhecido como humano, mas implica o dever de tornar-se racional. Ao homem natural convém o nome de animal; tal é o ponto de partida, mas não é o ponto final. Afirma-se, por conseguinte, a possibilidade e a necessidade da passagem do natural ao humano; a definição de humano não é dada na origem mas na realização histórico-cultural que cada ser humano confere a si mesmo como uma criação inter-humana social possível e desejada. Poder-se-ia chamar todo este longo e complexo processo como processo de humanização, descrito como paideia pelos gregos e cuja tradução latina como humanitas já aponta perda da dimensão de processo, indicando apenas características, mas que, talvez, não exprima todas as virtualidades que o enigma-homem encerra como possibilidade, ainda mais se considerarmos os dramáticos eventos do século $\mathrm{XX}$ em que os humanismos de toda sorte sossobraram, os ideais ufanos do iluminismo desencantaram, permitindo o surgimento do anti-humanismo.

\section{Sentido do humano}

\section{Scheler}

3. No entanto, tal interpretação e justificação é contestada por filósofos do século XX, por Max Scheler, H. Arendt e Levinas, entre outros. Scheler (2003) situa a inteligência como fazendo parte da natureza animal, não sendo exclusiva do ser dito humano; o mesmo se poderia dizer da ética, se esta for entendida como aliança entre razão e forças que derivam de dinamismos naturais a serem contidos e regulados em medidas sociáveis. Scheler deixa claro que o humano não pode consistir no que ele chama de construção psíquica, nem dele derivar nas etapas sucessivas em que se manifesta o desenvolvimento da vida (impulso sensitivo, instinto, memória associativa e inteligência prática) até chegar ao animal racional. A diferença essencial entre o animal racional e o humano dá-se por um novo princípio, oposto à vida em seus dinamismos e à vida do animal racional, chamado "espírito extra-vital" despreendido da vida orgânica e seus dinamismos e oposto à vida. 


\section{Arendt}

4. Hannah Arendt (2003) também situa a inteligência - contra a perspectiva da modernidade que via no animal rationale um ser diferenciado porque munido de força intelectual superior -, como fazendo parte da espécie animal, ligada ao processo biológico-evolutivo ao qual associa tanto o homo laborans como o homo faber. O especificamente humano surge com "palavras e atos", à guisa de um "segundo nascimento" (2003, p.189), em que se dá um novo início por iniciativa que rompe necessidades e utilidades. Mas não basta a ação, embora seja com ela que surja o novo que rompe a trama cósmico-biológica evolutiva e se dê um novo início; requer-se o discurso que indica e revela o sujeito da ação e estabelece entre os sujeitos a modalidade especificamente humana de relação. $\mathrm{O}$ ato de início é humanamente revelado mediante o discurso, com o qual os intervenientes podem identificar-se, revelar suas ações e construir um mundo humano.

\section{Levinas}

5. A conhecida expressão spinoziana conatus essendi (Ética, III) é tomada por Levinas para discutir a questão da vida e seus dinamismos; faz igualmente referência a uma idéia de Heidegger sobre a existência que existe no interessamento de si mesma (Sein und Zeit, § 9), e aproxima-as na sua repercussão de ordem ontológico-antropológica, operando uma distinção clara e incisiva entre o animal e o humano no homem. O pensamento de Spinoza e de Heidegger, conforme as breves indicações acima, poderia ser sintetizado na expressão - o esforço de preservar o próprio ser e nele perseverar contra ventos e marés - e receber diversas interpretações, como a história atesta. Aqui interessa explicitar o uso de Levinas que lhe confere dois sentidos principais: o do esforço, a significar a expressão corrente nos seus escritos como "força que vai" e se expande que, por ser natural, é tida como justificada em seu modo de ser e operar, mesmo ilimitadamente. Por ser natural e por levar na direção da vida e sua expansão, o esforço é considerado estrutural e inquestionável enquanto não se chocar de frente com outro com a mesma pretensão. Mas o próprio choque é considerado como natural e conseqüentemente a guerra é vista como inevitável, isto é, faz parte do cotidiano da vida dos homens e das sociedades. Esta seria uma crença inveterada que faz parte do pensamento ocidental. Levinas situa a "força que vai" do lado da animalidade, da filosofia biológica do racismo (cf. Rey, 190). O outro sentido diz respeito ao "seu" ser, sendo que o termo "seu" aponta para a propriedade e eticamente para o egoísmo. Mas egoísmo não deve ser considerado aqui imediatamente na ordem moral, procede e está ligado naturalmente ao esforço de perseverar no seu ser. Os dinamismos naturais teriam uma teleologia intrínseca que dirige sempre para o "seu" ser. O confronto entre os seres que são animados pela teleologia do "seu" ser parece assim inevitável e, por isso 
mesmo, natural. Os conflitos são naturalizados, dos quais decorrem a violência e, como extremo, a guerra, estas são justificadas na luta pelo seu ser contra o direito de ser do outro, de cada outro, de todos contra todos. Não há só uma ignorância do direito de ser do outro; há sobretudo uma ignorância do outro enquanto outro e da possível socialidade. O ser está tão tendido sobre o seu ser que produz interessamento exclusivo sobre si, ignorando o direito a ser do outro. A este interessamento é conferido o nome de "ontologia" (TI, HAH), outras vezes de "essência" (AE, DVI). Levinas levanta uma questão insólita, a meu ver de extrema atualidade, ao perguntar se "as energias animais do interessamento ao ser" não comandariam "o segredo do social, da luta, da derrota e da vitória" (ADV, 76-77). E acrescenta a seguir: "A persistência do animal no ser, o conatus, permanece de fato indiferente a toda justificação e a toda acusação". Parece coincidir com um direito natural e não compete a ninguém o direito de questioná-lo ou julgá-lo. Pode-se ir mais longe na reflexão: como a racionalidade está integrada no animal rationale, ela mesma é animada pelo mesmo dinamismo intrínseco da natureza que verte sempre para o "seu". A obra da razão, neste sentido, produz racionalizações e justificações no interessamento do próprio ser. Objetividade, imparcialidade, autotranscendência, conceitos puros nada mais são que estratégias da racionalidade para justificar o interessamento do eu que, no afã de perseverar no seu ser e avantajar-se, recorre a mil formas de ardis travestidos de coerência, lógica e universalidade. Sartre seja talvez o pensador que tenha compreendido e expressado da melhor forma o conflito insuperável entre tais egoidades racionais fixadas no interessamento suposto natural e por isso mesmo justificado e tido como insuperável.

6. O esforço de ser e a perseverança no seu ser estão ligados à vida e se manifestam em dinamismos. É possível desconstruir dinamismos sem repensar a vida e a subjetividade? Como pensar ou repensar a vida e a subjetividade? Fenomenologicamente, parece possível operar aqui uma redução da redução. Neste sentido, conviria revisitar a segunda seção intitulada "interioridade e economia" da obra Totalidade e Infinito, de Levinas. Aí, o eu, firmado o estatuto da separação, surge como vida nucleada em corporeidade e sensibilidade, perfaz unidade densa com intencionalidade sensível própria, diversa da intencionalidade perceptiva ou cognitiva. "Viver é viver de" ar, luz, calor, alimentos, como modalidade sem objetalidade e sem teleologia. O gozo de viver está explicitamente ligado à alimentação, que não é objeto do viver, mas sua modalidade de ser. Diz Levinas: "Relação última com a plenitude substancial do ser, com sua materialidade - o gozo abraça todas as relações com as coisas", e consiste no gozar "sem utilidade, em pura perda, gratuitamente, sem remeter a nada de outro, em pura despesa - eis o humano ... à igual distância do sistema da razão... e do sistema do instinto" (TI, 106-107). 


\section{Natureza e sentido do humano}

7. "Eis o humano", expressão surpreendente nesta altura da obra Totalidade e Infinito em que trata da vida-sensibilidade-gozo, unanimemente considerada base da vida animal e que Levinas proclama humana. Por que humana e não animal? Satisfazer necessidades, seguir dinamismos biológicos, obedecer a pulsões, tudo isto já está estruturado na natureza orgânica e não manifesta nenhuma novidade pois se aplica a todos os organismos. A novidade está precisamente na possibilidade ou descoberta da gratuidade, no viver em pura perda, no desinteressamento de seu ser em ruptura com a teleologia dinâmica e com a preocupação referida ao próprio existir interpretadas como naturais originárias por um ato cognitivo. Pode-se desvelar na própria base da vida, na sua forma de gozo, uma como inversão dos instintos, como uma dimensão ética que consiste na sua gratuidade ou desinteressamento, descoberta que constitui uma reviravolta na concepção naturalista e uma afronta a esta inveterada crença ocidental. No dizer de Levinas, "o amor da vida não se assemelha à preocupação de ser que conduziria à inteligência do ser ou à ontologia. $\mathrm{O}$ amor da vida não ama o ser, mas a felicidade de ser. A vida amada é o próprio gozo da vida... relação da vida com a vida... e não uma representação da vida" (TI, 118). A viva vive-se como vida. Por conseguinte, a vida enquanto amor e felicidade é imediatamente de outra ordem que preocupação ou interessamento, isto é, revela a possibilidade de outro modo de ser no "animal rationale", que pode ser chamada de "desinteressa-mento" ou "des-prendimento" mas, nem por isso, tem ou recebe de imediato uma conotação de ordem ética, por estarmos no coração da própria nucleação da vida.

8. É digno de nota o diálogo que se estabelece entre Philippe Nemo e Levinas a propósito da relação vida e morte, da luta entre interessamento e ser, e merece ser transcrito integralmente:

P.N. - "Mas se há temor pelo outro e não por si mesmo, é possível viver?

E.L. - É, com efeito, a questão que se precisa, enfim, colocar. Será que eu me devo ao ser? Será que pelo simples fato de ser, de perseverar no ser, eu não mato?

P.N. - Com certeza, agora que o paradigma biológico se nos tornou familiar, sabemos que toda espécie vive às custas de outra, e que no interior de cada espécie todo indivíduo substitui outro. Não se pode viver sem matar.

E.L. - Não se pode, na sociedade tal como funciona, viver sem matar, ou pelo menos sem preparar a morte de alguém. Por conseguinte, a questão importante do sentido do ser não é: por que existe alguma coisa em vez de nada, questão leibniziana tão comentada por Heidegger, mas: será que não mato pelo fato de ser? [...] O desabrochar do humano no ser ..., a crise do ser, o outramente que ser se demarcam pelo fato de que o mais natural se torna o mais problemático... Questionamento da perseverança ingênua e natural no ser. [...] Quero dizer que uma vida verdadeiramente humana não pode permanecer vida satisfeita na sua igualdade com o ser ... que o famoso conatus essendi não é a fonte de todo direito e de todo sentido" (EI, 119-121). 
9. Max Scheler situa o humano num princípio extra-vital que conduz ao desprendimento oposto ao dinamismo da vida. Levinas, por sua vez, faz uma distinção fundamental entre vida e ser natural ou animalidade, emergida de uma redução fenomenológica sobre o natural, a vida e sua representação, e assim descobre um des-interessamento ou generosidade no próprio desabrochar da vida em forma de amor e felicidade de viver que lhe permite a instauração de um processo crítico sobre a ingenuidade da interpretação que toma o natural como dado originário justificador da luta pelo ser e sua perseverança expansiva. Evidentemente, não há aqui negação da possibilidade de se viver a partir da interpretação que funda o individual e o social na crença do naturalismo. Haveria como que duas possibilidades de se viver como animais racionais: a da perseverança no ser e luta por sua expansão e a do des-interessamento-generosidade ou desprendimento oposto à vida e seus dinamismos. Sendo assim, o animal rationale pode não ser uma modalidade que, em si mesma, possa ser chamada de humana, se considerarmos as razões apontadas por Levinas, Arendt e Scheler. Não haveria superação da animalidade senão pela integração da mesma na humanidade, mas isto só ocorreria no des-interessamento em relação ao próprio ser em prol do Outro ou no desprendimento oposto ao dinamismo da vida, o que não se daria por evolução nem por ardis ético-racionais. Ora, isto vai requerer um questionamento por completo da crença na tese dóxica do chamado naturalismo que considera o animal rationale imediatamente como humano.

10. A pergunta que procede agora soa: Como o humano pode emergir do fundo natural da animalidade racional? Como o desfazimento da trama ou jogo do ser - des-interessamento - é possível? Como explicitar o desafio da humanização hoje, tanto em nível individual quanto social? A partir de uma condição desumana, como se pode pensar o humano sem a abstração do idealismo das Luzes, sem a má fé do humanismo herdado do século XIX, e além dos projetos de emancipação que viraram em alienação no século XX?

\section{Sentido humano e autonomia-heteronomia}

11. Na modernidade, o conceito de autonomia indica a superação da heteronomia, a possibilidade da libertação ante amarras e dependências de qualquer ordem, tanto na biológica como na dita metafísica. A possibilidade da emancipação baseava-se na exploração das virtualidades da razão pela qual, enfim, o homem e a sociedade podiam alcançar o plano de uma humanidade livre e independente. Para este fim, a razão reclama para ela mesma, como livre exercício e plenitude de autonomia, a tarefa de sua auto-fundação. Pretende dar a si mesma seu início, seus princípios, suas leis e assim garantir-se como norma em si mesma. Mas como ela não pode dar a si mesma sua própria origem senão em ato segundo, ela precisa, de alguma forma, recuperar ou suprir este retardo, o que era feito geralmente na interpretação da estrutura do conhecimento ao relacionar sensibilidade espontânea receptiva e formação de intuições/idéias como operação unitária. 
Ao introduzir uma intencionalidade da sensibilidade distinta daquela da consciência, Levinas abre um intervalo - "décalage", "laps de temps" - irrecuperável entre "passividade mais passiva que toda passividade" e consciência intencional, mostrando uma "ruptura" da "sincronia" (AE 107), do representável, um corte "do fio da consciência" (AE, 141). Nesse intervalo acontece um "envelhecimento", uma incarnação em que o sujeito "se passa" como passividade absoluta que escapa à consciência. Como conseqüência desta irrecuperabilidade, o sujeito perde sua autonomia, cai sua soberania de sujeito constituinte auto-fundante. Conceitos como "passividade", "vulnerabilidade", "traumatismo" e outros indicam a destituição da sujeito em sua pretensão de autofundar-se e justificar-se.

12. Evidentemente, não se trata aqui de recusar a racionalidade e sua tradição, mas de repensar uma subjetividade que não ignora ou não recusa sua condição primeira de passividade inintegrável sobre a qual ela se ergue "ex-posta", "vulnerável", "ex-pressa", trans-ida, e por isso mesmo perpassada por uma espécie de - "maladie de l'identité" (AE, 57). Nota-se um formidável esforço de Levinas em explorar as falhas ou fendas do que se poderia chamar de fragilidade/finitude da subjetividade para mostrar suas lacerações, permitindo inscrever e decifrar outra leitura (dizer), e ao mesmo tempo apontar por um lado a desmesura da pretensão da autonomia idealista e, por outro, o irrefletido da crença na tese objetivista-naturalista. A pergunta que procede, no entanto, pode ser expressa em termos como: Como é possível pensar as falhas do sujeito, as rupturas irrepresentáveis na consciência? Se observamos a tentativa levinasiana, ela procura conduzir a atenção para além do que aparece e para além das afirmações baseadas no aparecer, para além dos chamados "ditos"; conduz a uma atenção vigilante para o fenômeno originário ou esfera originária do próprio "Dizer", em que se faz ressoar um dizer de um sujeito reduzido, isto é, sem o refúgio da representação, inteiramente exposto e desnudado, pura incarnação, ao qual não caberia nem a categoria de ser. Então torna-se indesviável a questão: Alguém fala? "Ouem fala?" que substitui as tradicionais perguntas 'quem olha' ou 'o que diz' que requerem, na busca de sentido, um retorno da intencionalidade, uma re-flexão do eu sobre seus atos e sobre si mesmo (cf. AE, 60, nota 33). À pergunta "quem fala", corresponde o dizer que verte em palavra dita; daí surge o dizer como dom da palavra que uma vez exposta, não retorna mais, sobre ela não há mais controle, esvaindo-se a autonomia e o domínio sobre a mesma. O dizer aparece como ex-posto a outrem, livre de sentido determinado, pro-vocador, dom. Se há um autor, não é possível remontar do dizer ao dito, pois o dito requer o ouvinte para ser intérprete do dizer. A relação-linguagem entre quem diz e quem escuta torna-se mais importante que a objetivação e representação. Mas a relação só é possível tendo como condição de possibilidade o dizer como dom. Dizer-dom como "proposição feita ao próximo" (AE, 59-60) precede o sentido, é sua condição. ${ }^{1}$ Ao mesmo tempo, o dizer como

Na seqüência da citação, Levinas escreve "Signifiance baillée à Autrui" (AE, 60). Convém notar a etimologia do termo "signifiance", que deveria ser traduzido por signifiança e não significância. 
palavra dada a outrem abre a dimensão do tempo; o esforço da consciência intencional não consegue mais recuperar o dizer como tempo primordial, a consciência sempre repousará sobre sua condição, sobre o lapso que intervém entre o dizer e o dito, isto é, sobre o dom que é a própria subjetividade enquanto incarnação. Assim, a doação do dom é inseparável da carne (corpo próprio) enquanto incarnação. Para explicitar, pode-se tomar um texto antológico de Levinas:

A viravolta do Eu (Moi) em Si (Soi) - a de-posição ou a des-tituição do Eu (Moi) é a modalidade mesma do des-interessamento à guisa de vida corporal votada à expressão e ao dar, mas votada e não se devotando: um si apesar de si, na incarnação como a própria possibilidade de oferta, de sofrimento e de traumatismo". (AE, 65)

Encontramos, aqui, a mesma idéia já realçada em TI, ao analisar a vida como gozo, onde o viver foi descoberto e exposto como gratuidade, generosidade e dom, para além e mais profundamente do que a visada ôntico-naturalista. Em AE, A vida como incarnação é descrita na passividade extrema e ali se inscreve a própria incarnação à guisa de dizer e de dom, melhor como condição de todo dizer e d toda doação. Agora, doação significa generosidade das "entranhas" (AE, 99), pura ex-posição de Si, Dizer que sustenta todas as objetivações, todos os ditos que histórica e socialmente lhe podem ser feitas e aplicadas.

É dessa ex-posição ao outro que procedem, como condição, todos os atos que podem ser inscritos com dom, tais como dar o pão para saciar o faminto, a veste para vestir o nu, o remédio para curar o doente. "Dar o pão de sua boca ou dar a sua pele" revestem-se aqui de realismo insuperável, traduzem o Dizer o Dar em sua condição de corporeidade, como "juventude" (HAH, 100) "paciência e envelhecimento" (AE, 65). Trata-se, pois, aqui do "para o outro", "malgré soi”, em nível de sensibilidade, própria da incarnação.

\section{Sentido humano e alteridade}

Ao desconstruir as constituições operadas pela consciência intencional, ao reduzir o próprio eu puro reduzido husserliano, ao desanexar a subjetividade da eira do ser, Levinas aponta para uma nova concepção de subjetividade e da vida não mais imantada aos dinamismos lidos na tradição da crença naturalista, continuada de alguma forma por filósofos na tradição filosófica ocidental, ente outros, por Spinoza, Hegel e Heidegger. Em Levinas, pode-se descortinar uma nova concepção de subjetividade e de sociedade. Pode-se dizer que dois verbos aparecem como essenciais nessa formulação: Dizer e Dar. A vida, antes de ser vista como dinamismo que investe na própria expansão e interessada na permanência de si mesma, é primeiramente gozo, isto é, puro viver em forma de generosidade sabática, em profunda harmonia com o cosmos e a natureza, a partir do que se pode

Trata-se de sinal e confiança, fazer sinal confiando-se, confiar-se em sinal, confiar-se como dizer, como expressando dom. Ora, como se trata de subjetividade em devir, signifiança implica articulação da incarnação-corporeidade como linguagem e dom em anterioridade a qualquer dito, a doação como incarnação torna-se condição da própria possibilidade de dom. 
reinterpretar o pensamento antrópico-cósmico-evolutivo e mesmo o que hoje se denomina por ecologia. A tensão do viver interpretada como inclinação espontânea sobre si mesma é ato segundo, ato este que foi privilegiado pela tradição ocidental e tem gerado um modo de viver e coexistir que leva a uma sociedade de luta e de guerra, já que a espontaneidade que flui do viver como egoísmo é tida como natural e inquestionável. A subjetividade, por sua vez, decorre desta própria visão da vida. Se a vida é auto-expansão e busca de si e por si mesmo, o sujeito é aquele que faz dessa luta seu próprio viver como condição de sobrevivência. Mas se a vida for interpretada, na sua arcké, como gozo, como generosidade e gratuidade a perder de vista, a própria subjetividade pode assim receber uma nova interpretação, a partir da análise da sensibilidade/incarnação.

Será, portanto, possível chegar à concepção de uma subjetividade "mais antiga que o saber ou o poder" e "recusada" pela filosofia (AE, 104-105) e pôr em questão o sujeito da tradição que foi visto em sua superfície. Foi recusada, por um lado, a condição que é a própria subjetividade como ex-posição ou Dizer que suporta todos os ditos e, por outro, a subjetividade como dom ou generosidade em que se inscreve a responsabilidade pelo acolhimento da diferença enquanto diferença. Incarnação, dom, dizer são os conceitos propostos para exprimir a quebra da dialética e abrir para a diferença e a proximidade. Não são mais as categorias da representação e da objetivação que permitem acolher a diferença e garantir o respeito do outro. A subjetividade como dizer e como dom é condição, na forma do amor, da experiência por excelência da proximidade que, garantindo o estatuto da diferença, acolhe o diferente em sua diferença sem redução.

Pode-se, por conseguinte, questionar: Quem é o sujeito do conhecimento? O conhecimento não define a substancialidade do sujeito na filosofia moderna? Será que outro nome para definir a filosofia não é egologia? Já Buber havia rompido com este esquema idealista e definido o sujeito como relação, como inter-relação. O homem é encontro, é relação com o outro e com o mundo. O encontro com o outro é diálogo, linguagem.

Há aqui um ponto de radical importância e parece ser essencial para ir além do naturalismo e do idealismo. O que pode haver além do cósmico-naturalorgânico-evolutivo? O que pode haver além do consciente-lógico-intelectivo? O ser humano não faz ele parte de ambos os sistemas, o seu epígono mais desenvolvido, último elo de uma cadeia conhecida até hoje? Haverá uma diferença que valha como diferença nestes sistemas?

Visto sob outro ângulo, isto pode ser expresso de outra forma: No naturalismo, o ser humano, mesmo sendo o último e mais desenvolvido epígono da cadeia evolutiva, está inscrito num feixe de determinismos aos quais obedece, embora a liberdade seja descrita possibilidade de ruptura. No idealismo, a razão dita soberana e realizante de autonomia, acaba obedecendo às leis internas da lógica que a regula e conduz. Para onde ir que não seja retornar para o ponto de partida? O ser humano aparece inscrito num processo maior que ele mesmo, que todavia procura compreender e explorar de mil formas, mas ao cabo de tudo a ele sucumbe e nenhuma novidade sobrevive, tudo entra e submerge no "grande jogo" do ciclo da 
vida e da morte. Com este final inexorável, pode-se ter a coragem de afirmar que tanto o naturalismo como o idealismo são dois sistemas que têm como base, não a pretensa autonomia, mas a servil obediência e submissão ou aos condicionalismos cósmico-naturais-orgânicos ou às regras formais da lógica.

A pergunta que procede é: deve o homem resignar-se à imanência? Deve-se aceitar esta visão de ser humano imanente e sem saída? Será que o ser humano se deve à natureza, ao ser, à lógica, haverá outra alternativa? E se o sentido do humano não for obediência e submissão à natureza e à lógica, qual outro poderá sêlo, como mostrá-lo, como instituí-lo? Mais radicalmente ainda: haverá sentido? Deverá haver sentido, outro sentido?

\section{Referências}

ARENDT, H. A condição humana. 10ª Rio de Janeiro: Forense Universitária, 2003.

BUBER, M. Eu e tu. 2 ${ }^{\text {a }}$ São Paulo: Cortez \& Moraes, 1979.

HEIDEGGER, M. Ser e tempo. Petrópolis: Vozes, 2002.

LEVINAS, E. Totalité et infini. La Haye: M. Nijhoff, 1971.

. Humanisme de l'autre homme. Montpellier: Fata Morgana, 1972.

Autrement qu'être ou au-delà de l'essence. The Hague: M. Nijhoff, 1974.

De dieu qui vient à l’idée. Paris: J. Vrin, 1982.

Éthique et infini. Paris: Fayard, 1982.

Au dela du verset.

REY, La mesure de l'homme.

SCHELER, M. A posição do homem no cosmos. Rio de Janeiro: Forense Universitária, 2003.

SPINOZA Ética. Buenos Aires: Aguilar, 1973. 